\title{
CORRECTION
}

View Article Online

View Journal I View Issue

Check for updates

Cite this: J. Mater. Chem. C, 2018, 6, 9030

DOI: $10.1039 / c 8 t c 90133 c$

\section{Correction: Novel insight into the structure and properties of lead-free dielectric $\mathrm{Sr}_{3} \mathrm{TiNb}_{4} \mathrm{O}_{15}$}

\author{
Thomas A. Whittle, ${ }^{a}$ William R. Brant, ${ }^{a}$ Ray L. Withers, ${ }^{b}$ Yun Liu, ${ }^{b}$ \\ Christopher J. Howard ${ }^{\mathrm{c}}$ and Siegbert Schmid*a \\ Correction for 'Novel insight into the structure and properties of lead-free dielectric $\mathrm{Sr}_{3} \mathrm{TiNb}_{4} \mathrm{O}_{15}$ ' by \\ Thomas A. Whittle et al., J. Mater. Chem. C, 2018, DOI: 10.1039/c8tc00732b.
}

rsc.li/materials-c

The authors would like to add an Acknowledgements section to their article in order to acknowledge the facilities that have supported this work.

The Royal Society of Chemistry apologises for these errors and any consequent inconvenience to authors and readers.

\section{Acknowledgements}

Parts of this work were carried out at the Australian Synchrotron, the Bragg Institute at ANSTO and the ISIS Facility, Rutherford Appleton Laboratory. The authors would like to acknowledge the support from the facilities through the provision of beam time and the help of Dr Qinfen Gu (AS), Dr James Hester (ANSTO) and Dr Aziz Daoud-Aladine (ISIS) during the various data collections. Travel funding from the Australian Synchrotron and the Australian Institute for Nuclear Science and Engineering is also gratefully acknowledged.

\footnotetext{
${ }^{a}$ School of Chemistry, The University of Sydney, Sydney, NSW 2006, Australia. E-mail: siegbert.schmid@sydney.edu.au

${ }^{b}$ Research School of Chemistry, The Australian National University, Acton, ACT 2601, Australia

${ }^{c}$ School of Engineering, The University of Newcastle, Callaghan, NSW 2308, Australia
} 